\title{
Child Attachment Style as a Predictive Factor for Internalization and Externalization of Witnessing Community Violence
}

\author{
Bridgett Boxley \\ Juvenile Justice and Psychology, Prairie View A\&M University, Prairie, TX, USA \\ Email: Bridgett.Boxley@yahoo.com
}

How to cite this paper: Boxley, B. (2018). Child Attachment Style as a Predictive Factor for Internalization and Externalization of Witnessing Community Violence. Psychology, 9, 578-587.

https://doi.org/10.4236/psych.2018.94036

Received: January 19, 2018

Accepted: April 8, 2018

Published: April 11, 2018

Copyright $\odot 2018$ by author and Scientific Research Publishing Inc. This work is licensed under the Creative Commons Attribution International License (CC BY 4.0).

http://creativecommons.org/licenses/by/4.0/

\section{cc) (i) Open Access}

\begin{abstract}
Internalization and externalization of negative symptomology associated with witnessing community violence can manifest in a number of disorders in children. Of those disorders diagnosed in childhood, research has shown that conduct disorder, social anxiety disorder, post-traumatic stress disorder, oppositional defiant disorder, intermittent explosive disorder, and disruptive mood dysregulation have a potential link to witnessing violence. Internalization symptoms can manifest as depressive mood, low self-esteem, and deficits in social interaction, poor interpersonal relationships, behavioral difficulties, and an overall poor adjustment. Externalization symptoms typically manifest in outwardly aggressive behaviors like physical and verbal violence, destruction of property, self-harm or self-destructive behaviors, tantrums, and antisocial tendencies. This review seeks to investigate the relation between attachment styles and the internalization and externalization of symptoms associated with witnessing community violence among African American youths who live in a lower income urban portion of the inner city. This study seeks to answer the following questions: What is the relationship between school, gender, and age of the participant and the expression of symptomology, what is the relationship between attachment style and symptomology, does violence severity moderate the relationship between witnessing community violence and symptomology, does attachment style moderate the relationship between witnessing violence and symptomology, and does attachment style moderate the relationship between violence severity and symptomology?
\end{abstract}

\section{Keywords}

Behavior, Intervention, Community Violence, Disorders 


\section{Introduction}

Witnessing violence, in any form, is highly correlated with internalization and externalization of negative symptomology (Lynch, 2003). This can be particularly problematic in children, as it increases the likelihood for experiencing impairments of cognitive, physical, social, and emotional development. Community violence has traditionally been described as any form of violence seen in the individual's mesosphere which typically includes one's residential neighborhood (Aisenberg \& Ell, 2005). In South East Washington DC, for example, there are 165 schools in which $72 \%$ of the fifth and sixth graders and $61 \%$ of the first and second graders said that they have directly witnessed one or more acts of community violence. A study in 1991 found that a sample of 1000 African American children studied reported directly witnessing a robbery, shooting, stabbing, or murder in their neighborhood (Children Witness to Violence Project, 1992).

\section{Attachment Style as a Moderator}

Bowlby's Attachment Theory describes how a child can develop one of four attachment styles. The style of each child begins to form at birth and is considered to be fully formed by two years old (Capuzzi, Stauffer, \& O’Neil, 2016). The attachment styles seen most often in trauma victims are Anxious-avoidant insecure, anxious-resistant insecure, and disorganized/ disoriented. In children who are anxious avoidant insecurely attached there is a lack of trust in their primary care provider. The child becomes outwardly indifferent to their caregiver's attendance but will be internally anxious. Developmental complications associated with this attachment style are an inability to communicate emotionally, impaired interpersonal functioning, and a lack of confidence to explore one's environment (Capuzzi, Stauffer, \& O’Neil, 2016). In children who are anxious-resistant insecurely attached (also referred to as ambivalent), we see a confused emotional reaction of anger and helplessness towards their primary caregiver. Again, these children will react indifferently to the presence of their caregiver but will feel insecure. This attachment style is usually the result of summation of experiences in which the child has learned that they are unable to depend on their primary caregiver for their emotional needs due to the caregiver's inconsistency, lack of appropriate response, or outright neglect. In children with disorganized/disoriented attachment style, we say the most extreme emotional reactions to caregivers in which the child may appear to be in emotional distress. These children have developed this attachment style due to their caregiver's emotional state ranging from varying emotional extremes (depression, rage, strict, passive) resulting in the child potentially being fearful of them (Capuzzi, Stauffer, \& O'Neil, 2016). The outcome of the various negative attachment styles alone has the potential to negatively affect the child, and when the effect of a traumatic event is added, that potential becomes exacerbated. However, research shows that only a small portion of those who witness community violence will exhibit symptomology like the disorders discussed here and an even smaller amount of children will exhibit 
externalized symptoms. So where does the disparity in numbers lie?

Research shows that familial support and parental involvement help to buffer against the negative effects of witnessing community violence such as the internalization of symptoms (Hardaway, Sterret-Hong, Larkby, \& Cornelius, 2016). When the mother or family of the child experiences significant distress, the child who is exposed to significant community violence seems to not be as resilient as children who are in families that aren't stressed (Lynch, 2003). When examining what we know of effects caregivers emotional state on the attachment style of children, one might begin to see how attachment would be an important characteristic in determining the etiology of internalization and externalization of symptoms in children.

\section{Disorders Related to Community Violence}

One might say that internalized symptoms are inward emotional experiences. The manifestation of each group is defined as an inward or outward display of behavior. Internalization symptoms can manifest as depressive mood, low self-esteem, and deficits in social interaction, poor interpersonal relationships, behavioral difficulties, and an overall poor adjustment. Without early intervention, these symptoms can evolve into a number of chronic disorders that negatively impact quality of life.

Externalization symptoms typically manifest in outwardly aggressive behaviors like physical and verbal violence, destruction of property, self-harm or self-destructive behaviors, tantrums, and antisocial tendencies. These symptoms are particularly disconcerting given the nature of the acts and the potential trajectories for the child experiencing the symptoms. There is a full spectrum of disorders that can manifest as a result of trauma inflicted by witnessing acts of violence in one's community (Guerra, Huesmann, \& Spindler, 2003). Of those diagnosed in childhood, research has shown that conduct disorder, social anxiety disorder, post-traumatic stress disorder (Yoon, Steigerwald, Holmes, \& Perzynski, 2016), oppositional defiant disorder, intermittent explosive disorder, and disruptive mood dysregulation have a potential link to witnessing violence.

Conduct Disorder is defined by the Diagnostic and Statistical Manual of Mental Disorders ( $5^{\text {th }}$ edition) as an ongoing pattern of behaviors that mirror an overall disregard for the basic rights of others, a disregard for socially normative behaviors, and developmentally inappropriate behaviors. Conduct disorder symptoms often manifest as aggression towards people and animals, destruction of property, lying and stealing, and serious rule violations without remorse, empathy, or performance consideration. This particular disorder has overlap with the oppositional defiant disorder and intermittent explosive disorder (pp. 469-475). Oppositional Defiant Disorder is comprised of angry and overall defiant behaviors that typically include short temper, resentfulness including blaming others for one's mistakes, a tendency to argue with authority and/or actively defies authority, and intentionally annoying others. This can be seen in 
children as young as five years old (American Psychiatric Association, 2013: pp. 462-465). Intermittent Explosive Disorder can be seen in children as young as six and as old as eighteen years of age and is typically characterized by verbal and physical aggression that is out of proportion with the trigger situation, and aggression outburst appears to be impulsive instead of premeditated the aggression. To qualify as intermittent explosive disorder, the severity and unpredictability of the tantrum behaviors must result in significantly diminished quality of interpersonal relationships and overall life functioning (American Psychiatric Association, 2013: pp. 466-467). Disruptive Mood Dysregulation and Intermittent Explosive Disorder share a significant overlap in symptomology, as well. Disruptive Mood Dysregulation is described by the Diagnostic and Statistical Manual of Mental Disorders (fifth edition) as severe recurrent temper outbursts manifested verbally, and/or behaviorally with physically aggressive acts toward people and property. The outbursts tend to be out of proportion to the situation that triggered them, occur three to four times per week, and the overall mood of the child between outbursts is irritable. Like intermittent explosive disorder, the diagnosis can be made in children as young as six, and as old as eighteen years of age. The DSM acknowledges that the majority of children that receive mental health treatment in the United States will receive of Disruptive Mood Dysregulation which suggests that the prevalence is very high (American Psychiatric Association, 2013: p. 156). Social Anxiety Disorder shares some overlap with the aforementioned disorders, but with the addition of internalization symptoms. For example, a child with this disorder may throw tantrums when attempting to avoid social situations, however, the diagnosis is comprised of mostly divergent symptoms. In children, we see an aversion to social contact with both peers and adults that can manifest as crying and/or visibly fearful responses like shaking and sweating. In children, refusing to attend school is commonly seen with this disorder and children report a fear of being judged negatively by teachers and faculty (American Psychiatric Association, 2013: pp. 202-207). Lastly, we see Posttraumatic stress disorder which can manifest in any number of ways in children, and has significant overlap in diagnostic criteria with all aforementioned disorders. Posttraumatic stress disorder (PTSD) can be diagnosed in children as young as six in children who have experienced, witnessed, or learned of a direct threat to life or serious injury. The degree to which a child might display symptoms of PTSD will largely be dependent on the severity of the trauma event as well as the number of exposures to traumatic stimuli. Symptoms of PTSD can include, but are not limited to: intruding thoughts and memories associated with the traumatic event itself, nightmares, flashbacks, somatic responses when in the presences of trauma-related stimuli, avoidant behaviors (especially of trauma-related stimuli), and an overall negative mood, affect, and thought content (American Psychiatric Association, 2013: pp. 271-280).

\section{Effects of Witnessing Community Violence}

Research regarding community violence has shown that children often begin 
perpetrating verbal and physical violence towards others which can even evolve into abuse (Gorman-Smith, Henry, \& Tolan, 2004) (McMahon, Felix, Halpert, \& Petropoulos, 2009). Of the most commonly seen, but least studied, is sibling abuse. Sibling Abuse is comprised of a set of severely violent acts directed toward a sibling that is frequent in occurrence. Under this definition, it is estimated that about three out of four American children are considered a perpetrator and/or a victim of sibling abuse (Brody, Ge, Kim, Murry, Simons, Gibbons, \& Conger, 2003). The idea of sibling abuse likely remains controversial because of the familial dynamics involved as well as the sheer number of sibling altercations in normal functioning sibling relationships. Some may view it as normal some view it as a problem; however, sibling abuse differs from typical sibling interaction in several ways. To begin, in sibling abuse there is usually a power disparity as a result of significant difference in age, physical size, or strength between the two. Next, the frequency and duration of altercations are more intense than regular sibling fighting, and there is often pressure or secrecy that intensifies the fear response of the marginalized sibling. Sibling abuse can be seen most often in families in which there is a fundamental lack of appropriate parental supervision and intervention (Ceballo, Ramirez, Hearn, \& Maltese, 2003). This lack of parental involvement can lead to more increased severity of abuse like one might see in inappropriate sexual behavior. It is important to note that in sexual abuse cases involving immediate family dynamics, female children are more likely to be sexually abused or have inappropriate sexual contact with male siblings than fathers or even stepfathers. The consequences of negative sibling interaction only deepen the negative effects of witnessing community violence. Sibling abuse has been shown to cause interpersonal deficits, negative self-perception, sexual and behavioral dysfunction, and depending on the severity of the abuse, even PTSD.

Another common form of externalization symptoms in children is bullying. Bullying is typically compromised by repeated patterns of aggression intended to harm or distress others which can consist of physical, verbal, or sexual violence and aggression. Aggressive episodes are unprovoked by the victim and often involve an unequal power dynamic. It is difficult to estimate the prevalence of bullying in the United States due to reporting deficits, but research has found that between $17 \%-80 \%$ of children have been victim of bullying at some point in life. Research has shown that males are more likely to be physical bullies, and females are more likely to be social bullies. It is likely that this disparity in reporting is due to the fact that some cultures in this country view bullying as normative in childhood. However, characteristics of bullies do not fit normative development for children. For example, bullies tend to lack empathy, and they use violence as a means of persuasion or communication. These are abnormal qualities for children.

Perhaps the most severe and abnormal type of externalization of symptoms is intimate partner violence. Intimate partner violence involves acts of physical, 
verbal, and sexual aggression directs. Perpetrators of violent sexual behaviors can be male or females. Victims of intimate partner violence may experience anxiety, low self-esteem, depression/suicide, PTSD, anger, and blame. In addition, victims experience behavior problems like increased aggression, delinquent behavior, and substance abuse. Psychosocial deficits include social and cognitive abilities, underachievement in academic settings (Busby, Lambert, \& Ialongo, 2013; Nebbitt, Lombe, Lavelle-McKay, \& Sinha, 2014) poor conflict resolution, trouble processing, constant reactionary thought content, social withdrawal, and low empathy for others.

\section{Empirical Findings}

Research has demonstrated that there are several moderating factors for the effects of witnessing community violence for children. These moderators include severity and duration of incidence, age, gender, ethnicity, and the mother's parenting style and stress level, social support, and the characteristics of the child (Kaynak, Lepore, \& Kliewer, 2011). Also, it has been shown that if the parents are aggressive, the home environment is harsh, or the punishments are authoritarian, the child is more likely to externalize symptoms. Based on these findings, a number of nationally known interventions for community violence have taken place to intervene on behalf of children at the community level. For example, The Child Witness to Violence Project that is based out of Boston City Hospital began in 1992 and now serves over 150 children via counseling, outreach, and advocacy who have been exposed to violence and trauma events (Children Witness to Violence Project, 1992). Similarly, the Violence Intervention Program created in New Orleans in 1993 sought to put an end to negative interactions between children suffering from the effects of witnessing community violence and local police officers. New Orleans wards have some of the highest levels of violence in the country and so children in these areas have high levels of exposure to trauma inducing stimuli. The community banded together to create an education and training curriculum for police officers as well as a 24-hour hotline for advisory and consultation. These tools were created to assist officers in interacting and bonding with children who have been exposed to violence. The program helped to increase awareness of symptomology associated with the trauma of witnessing community violence (Osofsky, 1999). This particular intervention is crucial given the potentially aggressive nature of externalization symptoms, and the increased likelihood that police will be involved with afflicted children. Officers should be trained in recognizing trauma victims and how to respond to the appropriately without escalating the situation to worsen the trauma's effect on the child. Lastly, the Keeping Children Safe Program based on the research out of the University of Miami sought to address children's frequent exposure to violence in Miami's Dade County communities. This school-based intervention program educates teachers and faculty members in recognizing community violence-related trauma, as well as intervention techniques that seek to reduce in- 
ternalization and externalization of symptoms. This program has experienced success in assisting affected children to maintain academic functioning in spite of violence exposure (La Greca, Perez, \& Glickman, 2002).

Intervention and prevention for externalization of symptoms programs that have not been successful, but are frequently used are school settings are zero tolerance and "three strikes and you're out" philosophies. These interventions do not address symptoms, do not address trauma, and do not model correct behaviors. In addition, implementing consequences like suspension and expulsion only assist in increasing avoidant behaviors. Also, these types of punishment focused intervention can cause students to withhold information from adults to avoid punishment from the school or bullies. The world-renowned Olweus Bullying Prevention Program has been shown to decrease bullying and intimate partner violence via conflict mediations at the individual level, group interventions that focus on anger management, teach social skills, and coping skills (Hazelden Foundation, 2016).

\section{Limitations}

It is hard to identify true environmental effects given the nature of genetic and environmental interplay that can be seen when testing environment effects. This interplay is often referred to as the argument of Nature vs. Nurture. The necessary design elements for studies testing environmentally related risk factors are longitudinal study design, with-in subject comparison, and sufficient power to determine effect sizes. When looking at environmental risk factors, you must consider the following: is the risk factor of interest proximal (closely related) or distal (distantly related), what is the indicator of the risk factor and what is the mechanism in which it affects the behavior of interest? Lastly, we must consider the heterogeneity of the indicator of the risk factor as it pertains to generalizability of the results. Twin designs of monozygotic twins, for example, share all their segregating genes, so in experimentation, differences seen in behaviors between the siblings would be directly attributed to the environmental risk factor. Another useful design is adoptee studies in which the design aims to separate genetic-environmental risk mediation via the examination of within-subject change following adoption.

In claiming something as a risk factor for something else, in this case witnessing community violence as a risk factor for internalization and externalization of symptoms, it is difficult to demonstrate the mechanism of the risk factor; however, it is important that researchers examine this pathway. As mentioned before, community violence is prevalent in marginalized areas which put children at risk for disordered development. However, there is a host of risk factors associated with marginalization that are equally likely to produce disordered development in children. A study that was done by Nebbitt, Lombe, Lavelle-McKay, and Sinha (2014), examined the correlation between environmental factors associated with low economic status (i.e. risk factor of public housing), depressive 
symptoms, and academic performance in a sample of 220 black male students. The researchers found that delinquent behaviors in depressed, anxious, and impoverished youth were negatively correlated with academic performance. This means that as behaviors improved following the research intervention, academic performance improved. This finding is important because while children are school-aged, their self-efficacy can be largely connected to their academic performance and this self-efficacy is difficult to achieve and maintain when the child is disadvantaged. Although the researchers found similar symptomology in the sample of children, community violence was not considered as a contributory factor.

In the work published by Jonson-Reid, Davis, Saunders, Williams, and Williams (2005), academic self-efficacy, opposed to self-esteem, was found to be more critical to school success when dealing with Black children. This finding is important because there are so many intervention programs that are focused on self-esteem building which usually take away from the child's time spent doing school work. An example of this can be seen in extracurricular activities like sports and clubs. Children who are struggling academically may feel inclined to gravitate to extracurricular activities to buoy self-esteem, but this will only widen the gap of education performance and further damage academic self-efficacy (Kent Butler, Shillingford, \& Alexander-Snow, 2011). In this study, witnessing community violence had the potential to dramatically affect the children's academic performance; however, the intervention did not address the effect and yet was able to yield an effect.

In the case of community violence exposure, poor academic performance would be considered distal sequelae. A more medial effect of community violence exposure status might be something like family stress level. A possible proximal implication of community violence exposure would be the increased rates of developing negative health outcomes like hypertension and depression. The relationship between community violence exposure and any number of associated negative outcomes is not causal because of multiple interactions, however, it is possible for clinicians to intervene with mediating and moderating interventions that affect the developmental trajectory of the child by decreasing the impact of known negative correlates. It is important to note that the malleability of each negative correlate requires further study to understand whether an intervention would make a difference, and if so, what the magnitude of that difference would have on the child's life. Understanding malleability and magnitude are important in determining the monetary and time costs associated with an intervention so that the intervention is appropriate for the child and their family.

\section{References}

Aisenberg, E., \& Ell, K. (2005). Contextualizing Community Violence and Its Effects: An Ecological Model of Parent-Child Interdependent Coping. Journal of Interpersonal Violence, 20, 855. https://doi.org/10.1177/0886260505276833 
American Psychiatric Association. (2013). Diagnostic and Statistical Manual of Mental Disorders (5th Edition). Arlington, VA: American Psychiatric Association.

Brody, G. H., Ge, X., Kim, S. Y., Murry, V. M., Simons, R. L., Gibbons, F. X., \& Conger, R. D. (2003). Neighborhood Disadvantage Moderates Associations of Parenting and Older Sibling Problem Attitudes and Behavior with Conduct Disorders in African American Children. Journal of Consulting and Clinical Psychology, 71, 211-222.

https://doi.org/10.1037/0022-006X.71.2.211

Busby, D. D., Lambert, S., \& Ialongo, N. (2013). Psychological Symptoms Linking Exposure to Community Violence and Academic Functioning in African American Adolescents. Journal of Youth \& Adolescence, 42, 250-262.

https://doi.org/10.1007/s10964-012-9895-Z

Capuzzi, D., Stauffer, M. D., \& O’Neil, T. (2016). Theories of Human Development. In D. Capuzzi, \& M. D. Stauffer (Eds.), Human Growth and Development across the Lifespan: Applications for Counselors (pp. 25-54). Hoboken, NJ: Wiley.

Ceballo, R., Ramirez, C., Hearn, K. D., \& Maltese, K. L. (2003). Community Violence and Children's Psychological Well-Being: Does Parental Monitoring Matter?. Journal of Clinical Child \& Adolescent Psychology, 32, 586-592.

https://doi.org/10.1207/S15374424JCCP3204_11

Children Witness to Violence Project. (1992). http://www.childwitnesstoviolence.org/

Gorman-Smith, D., Henry, D. B., \& Tolan, P. H. (2004). Exposure to Community Violence and Violence Perpetration: The Protective Effects of Family Functioning. Journal of Clinical Child \& Adolescent Psychology, 33, 439-449.

https://doi.org/10.1207/s15374424jccp3303_2

Guerra, N., Huesmann, R., \& Spindler, A. (2003). Community Violence Exposure, Social Cognition, and Aggression among Urban Elementary School Children. Child Development, No. 5, 1561. https://doi.org/10.1111/1467-8624.00623

Hardaway, C., Sterrett-Hong, E., Larkby, C., \& Cornelius, M. (2016). Family Resources as Protective Factors for Low-Income Youth Exposed to Community Violence. Journal of Youth \& Adolescence, 45, 1309-1322. https://doi.org/10.1007/s10964-015-0410-1

Hazelden Foundation. (2016). Olweus Bullying Prevention Program/Violence Prevention Works.

http://www.violencepreventionworks.org/public/olweus_bullying_prevention_program .page

Jonson-Reid, M., Davis, L., Saunders, J., Williams, T., \& Williams, J. H. (2005). Academic Self-Efficacy among African American Youths: Implications for School Social Work Practice. Children \& Schools, 27, 5-14. https://doi.org/10.1093/cs/27.1.5

Kaynak, Ö., Lepore, S. J., \& Kliewer, W. L. (2011). Social Support and Social Constraints Moderate the Relation between Community Violence Exposure and Depressive Symptoms in an Urban Adolescent Sample. Journal of Social \& Clinical Psychology, 30, 250-269. https://doi.org/10.1521/jscp.2011.30.3.250

Kent Butler, S., Ann Shillingford, M., \& Alexander-Snow, M. (2011). African American Male Students and the Achievement Gap: Building a Successful Student/Citizen. Revista Interamericana De Psicología, 45, 177-184.

La Greca, A. M., Perez, L. M., \& Glickman, A. (2002). Keeping Children Safe: A Program to Help Children Cope with Community Violence. Coral Gables, FL: University of Miami.

Lynch, M. (2003). Consequences of Children's Exposure to Community Violence. Clinical Child \& Family Psychology Review, 6, 265-274.

https://doi.org/10.1023/B:CCFP.0000006293.77143.e1 
McMahon, S. D., Felix, E. D., Halpert, J. A., \& Petropoulos, L. N. (2009). Community Violence Exposure and Aggression among Urban Adolescents: Testing a Cognitive Mediator Model. Journal of Community Psychology, 37, 895-910.

https://doi.org/10.1002/jcop.20339

Nebbitt, V. E., Lombe, M., Lavelle-McKay, C., \& Sinha, A. (2014). Correlates of Academic Performance among School-Age African American Males in Public Housing. Children and Youth Services Review, 4465-4471.

Osofsky, J. (1999). The Impact of Violence on Children. Future of Children, 9, 33-49. https://doi.org/10.2307/1602780

Yoon, S., Steigerwald, S., Holmes, M. R., \& Perzynski, A. T. (2016). Children's Exposure to Violence: The Underlying Effect of Posttraumatic Stress Symptoms on Behavior Problems. Journal of Traumatic Stress, 29, 72-79. https://doi.org/10.1002/jts.22063 